\title{
The Introduction of Chinese Laser Material Processing and Market
}

\author{
Xiao ZHU and Jiayu WANG \\ National Engineering Center for Laser processing, 1037 Luoyu Road, Wuhan, P. R. China
}

(Received October 30, 2014)

\begin{abstract}
China is playing an import role and nearly the largest market in laser industry. In China there are more than one thousand laser companies and four large laser industry clusters. National research institutes and universities provide laser technology and industry focuses mainly on the development of laser equipment and machine. The total revenue of laser material processing reached 40 billion Yuan (about 6.5 billion US Dollar) in 2013. This article gives a brief review of the current status and outlook of Chinese laser industry.
\end{abstract}

Key Words: Chinese laser, Industrial laser, Optics valley

\section{Article}

In July 1960 the first ruby laser in the world was invented by T. H. Maiman. Just half year later in 1961 the first ruby laser in China was successfully developed by Chuangchun Institute of Optics, Fine Mechanics and Physics. In the past five decades Chinese laser technology and industry have well developed. In recent years the Chinese laser market size grow very rapidly, the compound average growth rate exceeded 25\% between 2006-2010. In 2009 Chinese laser market grew 15\% exceeding 10 billion Yuan, while the world laser market slid. In 2010 the world economy started recovery and Chinese laser market exceeded 13.5 billion Yuan, benefiting from the strong demand on laser processing equipments.

Currently the performance and quality of Chinese laser products are preliminarily competitive to foreign products. The Chinese domestic laser market include laser components and systems, laser processing machines, optical communication components and equipments, laser measurement equipments, medical laser equipments. Industrial processing and optical communication have more than $70 \%$ of total laser market share (see Fig. 1).

Nationwide there are five national laser technology centres and more than ten laser research institutes. In twenty-one

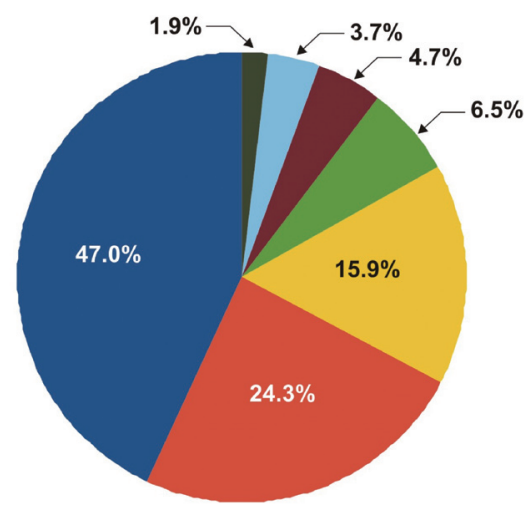

- Laser processing Optical communications - Lase measurement - Laser and laser system - Laser components Laser medical treatment - Others

Fig. 1 Laser applications market share (Source: Forward Industry Research). provinces there are manufacturing and sales of laser products. A complete laser industry chain is already established in China, covering from laser crystals and material, components and accessories, laser and laser systems, machines and applications. In 2013 the total sales of Chinese laser equipment reached 30 billion Yuan, the total business of Chinese laser industry is 75 billion Yuan.

Since the overall market recovery of Chinese manufacturing industry the domestic laser industry grows more than $25 \%$ annually. Simultaneously the export of Chinese laser products is rising and is expected to exceed 5 billion US Dollar in 2015.

\section{Chinese laser industry clusters}

There are already more than thousand laser enterprises in China, locating mainly in the economically developed provinces and cities such as Hubei, Beijing, Jiangsu, Shanghai, Shenzhen and Guangdong, contributing more than $90 \%$ of total domestic sales. The development of Chinese laser industry is very unique and geographically organized in the form of cluster. Today there are four main laser industry clusters-central China, east China, south China and Circum-Bohan-see region, providing and targeting different laser products, machines and applications (see Fig. 2).

\subsection{Central China cluster}

Optics Valley in Wuhan is the most famous laser cluster in China. Wuhan geographically locates by Yangtse River and in central China. It is the home of Chinese laser industry and more than two hundreds laser companies, contributing more than half of the revenue of Chinese laser industry. The cluster is based on Huazhong University of Science and Technology and the national laser engineering centre which provide laser and application technology development and know-how transfer. The laser system manufacturers also develop own laser systems and are already able to produce solid state laser, fiber laser, diode laser and $\mathrm{CO}_{2}$ gas laser with output power up to several kilowatts at wavelengths from ultraviolet to infrared. The laser machine manufacturers, among them some are also laser system manufactures, supply various laser based machines for different applications. Some of them cooperate 


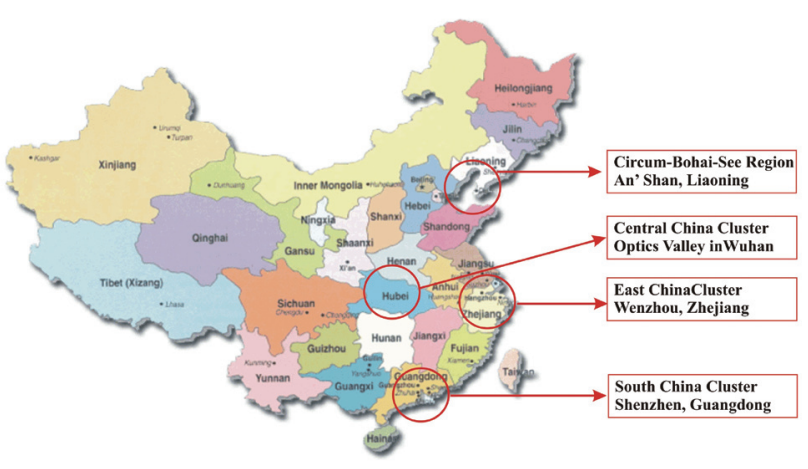

Fig. 2 Chinese laser clusters and their locations.

with local large steel plant and automotive factories, developing and supplying tailored machines and production lines. In this cluster HuaGong Laser is the largest player contributing more than 1.7 billion Yuan turnover in 2013.

\subsection{East China cluster}

East China is the core economically developed area including Shanghai, Jiangsu and Zhejiang provices. In this area traditionally there are a lot of small- to-middle size enterprises which have large demand on equipment and machines. In 2011 the Chinese Ministry of Science and Technology decided to set up a large laser and optoelectronics industry cluster in Wenzhou which locates near Shanghai and East China sea. Currently there are more than eighty laser and opto-electronics companies residing in Wenzhou, among them more than twenty companies are in the laser industry. In 2012 total revenues of Wenzhou cluster reached nearly 30 billion Yuan.

\subsection{South China cluster}

Shenzhen and surrounding area locate near Hongkong. Since economical reform and opening in 1980s the local economics keeps fast rising due to geographical advantage and tight connection to Hongkong. Now it becomes a very important economical area in China. In this area many laser and optoelectronics companies were founded, providing products from single components to large laser machines. Han's Laser is the largest laser company in this area with turnover of 4.3 billion Yuan in 2012 .

\subsection{Circum-Bohan-see region cluster}

Historically An'Shan in provice Liaoning is the base of Chinese heavy industry producing trucks, machine tools and large machines. An'Shan High Technology Development Zone was established in 1992. In 2011 laser industry became a new and very important development direction in this zone, targeting laser systems, laser cutting and welding machines, optical communications, laser medical treatment and laser surface treatment services.

\section{Laser industry in province Hubei}

Hubei is one of the pioneers of laser research and application in China. Nowadays it already becomes the largest base of laser technology research, laser industry and laser professional training in China. Famous Optics Valley locates in the province capital Wuhan and is the largest one of four Chinese laser industry clusters.

In the last years the laser industries in Hubei kept on growing. The industry production arose from 12 billion Yuan in 2009 to 20 billion Yuan in 2012. There are more than 200 companies in laser industry and 50 among them are large en-

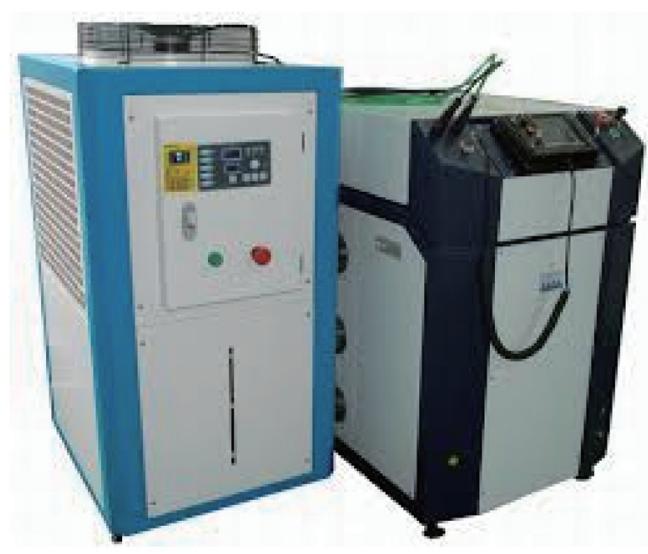

Fig. 3 A typical laser welding machine based on YAG pulsed laser manufactured in Wuhan.

terprises. These companies form the groups in different fields and applications including industrial laser, medical laser, laser and optical components (see Fig. 3). The laser sales from Hubei contributes about $50 \%$ of the total sales in domestic market.

In 2012 the Optics Valley Industry Foundation with initial 10 billion Yuan capital was founded in Wuhan. This foundation aims to set up the Chinese largest laser industry park and the first Chinese laser theme park in Zuoling, about $15 \mathrm{~km}$ east to Donghu New Technology Development Zone where Optics Valley locates.

\section{Industrial laser technology in China}

Laser development is conducted by both research institutes and commercial companies. The research institutes focus on new laser technology for the future, while the companies mainly on improvement and optimization of the current laser systems such as power increase. China has made much progress in fiber laser, solid state laser, gas laser and diode laser which are very often used in industry.

Raycus Fiber Laser Technology produced the first fiber laser and achieved commercialization in China. Currently more than 20 Chinese companies produce and supply fiber laser from pulsed low power to continuous-wave high power up to $4 \mathrm{~kW}$. Last year the first $10 \mathrm{~kW}$ fiber laser system was successfully developed in China and it is also the second one worldwide behind IPG. Several components such as pumping diode modules, combiners and Bragg gratings for low to middle power lasers can be manufactured by Chinese local companies and are already integrated in the commercial products. However, other parts such as laser diode chips and high-quality doped active fiber are still not available and have to be purchased from abroad. Strategically the state and large companies are investing a lot of resources to design and produce product-level diode chips and active fiber, aiming to achieve vertical integration as IPG.

The solid state lasers are widely used for material processing such as cutting and welding. Due to low ownership costs the lamp-pumped solid state lasers are still popular for smallto middle-size mechanical processing users. They continue to be optimized to increase beam quality and power for faster processing. In the field of diode-pumped solid state laser Chinese companies are already able to produce a series highquality pulsed lasers from ultraviolet to infrard wavelengths for precision processing. These lasers have already been exported to USA and Europe. It has to be mentioned that a kilowatt diode-pumped thin disk laser was successfully developed 


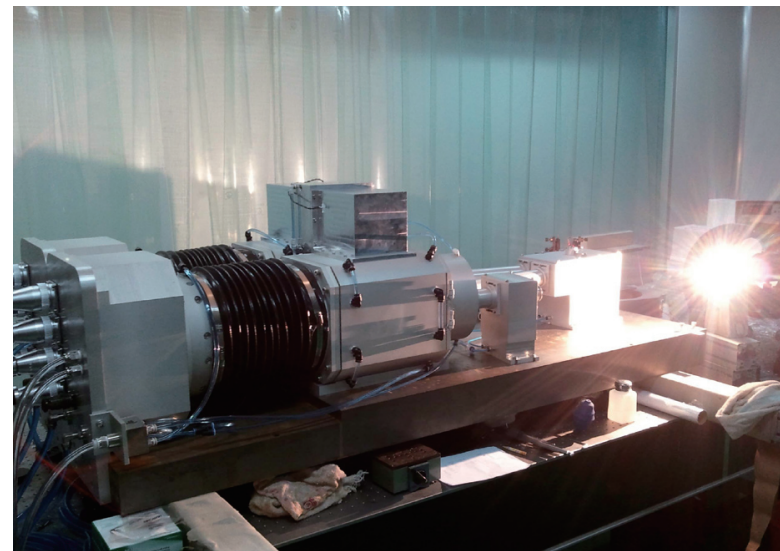

Fig. 4 Diode-pumped thin disk laser developed by National Laser Processing and Engineering Research Center in Wuhan.

by National Laser Processing and Engineering Research Center in Wuhan last year (see. Fig. 4). This disk laser utilizes a novel patented pumping optics which is completely different from the method used by Trumpf. The commercialization, further performance improvement and development of thin disk laser serie are going on.

For a long time $\mathrm{CO}_{2}$ gas laser has been used in marking, cutting and welding. Although low conversion efficiency it still has a certain market share on material processing. Currently China is able to develop and manufacture high power fast axial $\mathrm{CO}_{2}$ laser. With cooperation with National Laser Processing and Engineering Research Center in Wuhan a series of high power $\mathrm{CO}_{2}$ lasers from $2 \mathrm{~kW}$ up to $10 \mathrm{~kW}$ have been commercialized and introduced to the market.

Due to compact size and high wall-plug efficiency the diode laser is more and more used in material processing and medical treatment. In low power range up to several watts there are some companies providing different diode products for optical communication, illumination, positioning and medical treatment, etc. High power free-space direct diode lasers with several kilowatts output are available mainly for surface treatment. Fiber-coupled diode lasers, especially high-brightness diode lasers with small fiber core are also being developed for pumping and cutting applications. Currently the main weakness is laser diode chips and high-quality micro transformation optics which have to be imported. The state and companies have realized these problems and are endeavoring to close these gaps in diode laser product chain.

\section{Chinese market outlook of laser processing}

The Chinese government is an nonnegligible factor in support and promotion of laser applications. In the mid- to longterm state strategy the laser processing technology has been selected in the key supporting programs. The laser processing have been regarded as a core technology by Chinese government to strengthen the manufacturing industry. Annually the companies and institutes obtain a lot of financial aid to develop new technology and applications and to install and expand production capacity.

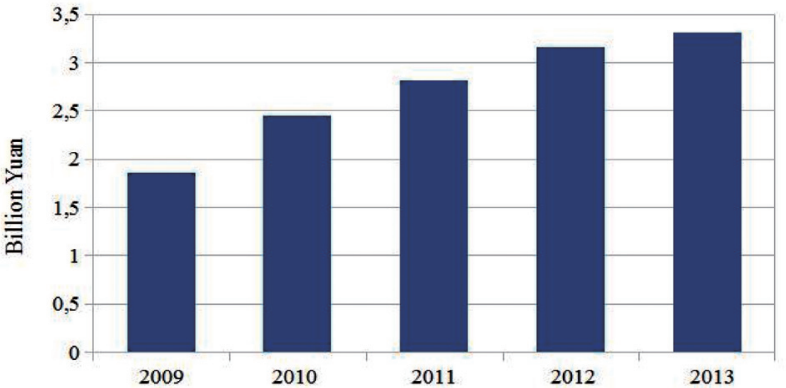

Fig. 5 Chinese market sales of laser cutting machines (source: ZhongKe Strategy).

Industrial laser processing equipments and machines were at first introduced and used in economically developed regions in China. About ten years ago in province Guangdong there were already about 1500 laser marking machines, 800 laser welding equipments and more than $20 \mathrm{CO}_{2}$ laser cutting machines. In the past years the market of laser equipments and machines has extended from economically developed regions to other regions especially in west China. Laser processing is being more and more adopted by manufacturers partly because of improved laser technology. Another main reason is that the prices of laser equipments and initial purchase costs keep on declining, which makes the users willing to apply this new technology to increase the production efficiency and improve the product quality.

With the expanding economy and innovation and progress of laser processing technology and applications, the laser application markets are expanding from traditional light industry to the fields of electronics, machine manufacturing, automotive manufacturing and aerospace, etc. Figure 5 shows the sales growth of laser cutting machines in the last five years. It is conservatively estimated that the Chinese industrial laser sales will have an annual growth of roughly $20 \%$ in the next five years, reaching 100 billion Yuan in 2019.

Fiber laser is currently the most popular industrial laser and has the largest contribution to the market growth. Due to high conversion efficiency and low maintenance costs fiber lasers are more and more used for laser processing. Fiber laser processing equipments have high reliability, while their prices are declining every year. Low power pulsed fiber laser has already replaced conventional lamp- and diode-pumped solid state laser for marking and carving. High power kilowatts continuous-wave fiber laser is becoming new laser source for metallic sheet cutting, occupying most market share of $\mathrm{CO}_{2}$ laser. The current Chinese market of high power killowatt fiber laser is dominated by IPG, SPI and domestic Raycus.

Ultrafast pulsed laser will be another market driving force. Picosecond and femtosecond diode-pumped solid state and fiber lasers are entering laser processing market and are used in micro processing fields. They have been demonstrated to be a very suitable laser sources for precision processing such as fine drilling and pipe welding. These lasers are opening new laser applications and will have the most rapid sales growth in the next years. With the development of new smart phones the sapphire cutting is becoming new application and has strong demand on pulsed laser with high peak power. 